\section{Butt really? The environmental impact of cigarettes}

Are cigarette butts more than just an unsightly litter problem? Do the chemicals leached out of them just 'go away'-biodegraded and diluted by our streams, rivers and oceans so that we can forget about them? This special supplement of Tobacco Control brings together the currently known science about cigarette butt waste and sets the stage for a new research agenda that can unite the tobacco control community with environmental activists who have long been appalled by the single most commonly collected waste item found each year on beach clean-ups. In addition, butts are also reported to comprise an estimated 25-50 percent of all collected litter items from roads and streets-making them a concern for the quality of urban life. Cigarette butts contain all the carcinogenic chemicals, pesticides, and nicotine that make tobacco use the leading cause of preventable death worldwide, yet they are commonly, unconsciously and inexcusably dumped by the trillions ( 5.6 trillions and counting) into the global environment each year.

In this issue, Moerman and Potts demonstrate the presence of heavy metals in cigarette butt leachates-the toxic soup produced when butts are soaked in water; Slaughter shows that only one cigarette butt will kill half the fish exposed to leachates in a controlled laboratory setting; Harris describes the history of how tobacco companies used filters as

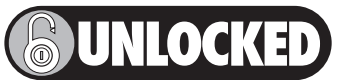

This paper is freely available online under the BMJ Journals unlocked scheme, see http://tobaccocontrol. bmj.com/site/about/unlocked.xhtm

\footnotetext{
${ }^{1}$ American Legacy Foundation, Washington, DC, USA; ${ }^{2}$ Department of Health Behavior, Roswell Park Cancer Institute, Buffalo, New York, USA; ${ }^{3}$ Graduate School of Public Health, San Diego State University, San Diego, California, USA

Correspondence to Dr Cheryl G Healton, CEO, Legacy, American Legacy Foundation, 1724 Massachusetts Ave, NW, Washington, DC 20036 USA;

chealton@americanlegacy.org
}

a marketing tool in an effort to allay fears about the harm caused by cigarettes, even after the companies knew that filters did not reduce risk. Smith and Novotny reveal the tobacco industry's long-standing concern about the cigarette butt problem and how it has responded by shifting responsibility for the job of cleanup back to its victims. Schneider et al analyse tobacco product litter as an economic issue, with costs of cleanup borne by communities instead of the tobacco manufacturers. Barnes describes some important regulatory and environmental principles that should underlie efforts to mitigate cigarette butt waste, including the Precautionary Principle-which states that environmental harm does not have to be proved to justify preventing potential exposures-and Extended Producer Responsibility-which asserts that those who produce a toxic waste product should be held accountable for its cleanup.

To grapple with toxic cigarette butt waste, we can look for lessons in other interventions against environmental pollution:

- 'Bottle bills', in which states apply a deposit-return scheme, have greatly reduced waste from disposable bottles, cans and plastic containers; the electronics industry collects a fee on computers and other equipment to be used for recycling these devices instead of simply throwing them into landfills. Waste fees or a deposit-return scheme could be applied to cigarettes to recoup the costs of cleanup in individual communities.

- Plastic bags have been banned in a number of communities, and plastic tampon inserters have been considered for regulation by several states as environmental hazards and beach blight. The plastic (cellulose acetate) cigarette filter could also be banned to reduce a huge source of unsightly, non-biodegradable plastic waste.

- Mandatory take-back policies, such as in those in the European Union for electronics or as proposed in San
Francisco for pharmaceuticals that have expired, may be implemented to reduce cigarette butt waste, invoking the principle of Extended Producer Responsibility.

- Prohibitions on smoking in enclosed spaces have reduced indoor air pollution and related health risks for millions. Certainly, prohibitions on smoking in outdoor public places, including parks, beaches and even outdoor urban areas will prevent some butt waste flowing into our aquatic environments. College campuses, as suggested by Sawdey et al with the current wave of green consciousness, should be the vanguards of this effort-they should all be smoke free, healthy environments, with no butts about them.

We need to determine which chemicals in combusted cigarette waste kill aquatic organisms and whether these chemicals can be detected, much like discarded antibiotics and other chemicals are detected, in our water systems. Researchers should also examine the social and economic impacts of cigarette waste, including costs to localities for butt clean-up and degradation of urban environments.

While more research would certainly be helpful to define the scope of the problem, science-based interventions should now address what is clearly an unnecessary and preventable environmental plague in our communities. If filters on cigarettes don't make smoking less hazardous why should they be used at all? Filters don't make smoking any safer although most smokers today would seem to still think otherwise.

Butt really, what is needed now is for tobacco control and environmental activists to work together to hold the global cigarette industry accountable for the toxic mess they've caused. It is their products, when used as directed and then discarded as part of the smoking ritual, that pollute our environment, not just our hearts and lungs. Cigarette butt waste is the last socially acceptable form of littering in what has become an increasingly health and environmentally conscious world. We challenge our friends and colleagues in tobacco control and environmental change movements to join forces and find solutions for eliminating this especially toxic form of trash.

Provenance and peer review Not commissioned; not externally peer reviewed.

Tobacco Control 2011;20:i1. doi:10.1136/tc.2011.043729 